\title{
O DESAFIO DA ICONOGRAFIA: UM BALANÇO HISTORIOGRÁFICO DA CARICATURA A PARTIR DA NOVA HISTÓRIA
}

\author{
Rosildo Raimundo Brito ${ }^{1}$
}

\begin{abstract}
RESUMO: Este artigo é fruto de uma pesquisa bibliográfica sobre a apropriação da caricatura enquanto fonte para a historiografia, com ênfase na abordagem apresentada a partir da Nova História. Para tanto é apresentado um breve balanço acerca do percurso da documentação visual no domínio da História, destacando-se o lento e problemático trajeto de legitimação que caracterizou a inserção da iconografia satírico-humorística no universo da historiografia. $\mathrm{O}$ trabalho se pauta em registros pontuais apresentados por historiadores de temporalidades distintas e com importantes contribuições no campo da historiografia do humor gráfico, dentre os quais se destacam George Minois; E.H. Gombrich; Michel Vovelle; Marcos Silva e Ulpiano Meneses, tendo como principal objetivo, proporcionar uma maior compreensão em torno dos avanços e desafios que os estudos sobre a caricatura apresentaram e ainda apresentam para os historiadores da contemporaneidade.
\end{abstract}

PALAVRAS-CHAVE: História; Nova História; Iconografia; Caricatura.

\section{THE CHALLENGE OF ICONOGRAPHY: A HISTORIOGRAPHIC BALANCE OF CARICATURE FROM THE NEW HISTORY}

\begin{abstract}
This article is the result of a bibliographical research about the appropriation of caricature as a source for historiography, with emphasis on the approach presented from the New History. In order to do so, it is presented a brief balance of possible ways in the use of visual documentation in the domain of History, highlighting the slow and problematic path of legitimation that characterized the insertion of satirical-humoristic iconography in the universe of historiography. The work is based on punctual records presented by historians of distinct temporalities and with important contributions in the field of graphic humor historiography, among which stand out George Minois; E.H. Gombrich; Michel Vovelle; Marcos Silva and Ulpiano Meneses, whose main objective is to provide a better understanding of the advances and challenges that studies on caricature presented and still present to historians of the contemporaneity.
\end{abstract}

KEYWORDS: History; New history; Iconography; Caricature.

\section{EL DESAFÍO DE LA ICONOGRAFÍA: UN BALANCE HISTORIOGRÁFICO DE LA CARICATURA A PARTIR DE LA NUEVA HISTORIA}

RESUMEN: Este artículo es fruto de una investigación bibliográfica sobre la apropiación de la caricatura como fuente para la historiografía, con énfasis en el enfoque presentado a partir de la Nueva Historia. Para eso se presenta un breve balance sobre el recorrido de la

\footnotetext{
${ }^{1}$ Doutorando em História Social pela Universidade de São Paulo (USP). Professor Adjunto da Universidade Federal de Campina Grande (UFCG).
} 
documentación visual en el dominio de la historia, destacándose el lento y problemático trayecto de legitimación que caracterizó la inserción de la iconografía satírico-humorística en el universo de la historiografía. El trabajo se pauta en registros puntuales presentados por historiadores de temporalidades distintas y con importantes contribuciones en el campo de la historiografía del humor gráfico, entre los cuales se destacan George Minois; E.H. Gombrich; Michel Vovelle; Marcos Silva y Ulpiano Meneses, teniendo como principal objectivo, proporcionar una mayor comprensión en torno a los avances y desafíos que los estudios sobre la caricatura presentaron y aún presentan para los historiadores de la contemporaneidad.

PALABRAS CLAVE: Historia; Nueva Historia; Iconografía; Caricatura.

\section{INTRODUÇÃO}

Não é de hoje que se afirma que vivemos numa sociedade fortemente caracterizada pelo dinâmico processo de profusão de imagens. Trata-se aqui, de um dos fenômenos que melhor define a modernidade e, de maneira ainda mais particular, o mundo hodierno em que o apelo às sensações visuais se intensifica e modela todo o cenário cotidiano, fazendo das imagens, em seus mais variados gêneros, um objeto de estudo que se apresenta cada vez mais provocativo e desafiante aos olhos dos mais diversos pesquisadores das ciências humanas e sociais. E, aos poucos tem se percebido que a imagem ontologicamente tramada através de processos históricos se define em meio a um complexo jogo entre visualidades, discursos, poderes, linguagens e processos de significação coletivos partilhados e entremeados a processos de subjetivação e operações de memória-esquecimento.

Seja artefatos cultuais ou produtos recorrentes de uma cultura visual, aquilo que o historiador francês Marc Ferro (1992), denomina de imagem-objeto, aponta para um rico e complexo universo constituído por elementos que se integram ao mundo, comunicando, significando, fazendo da visualidade, uma dimensão valiosa da vida social. Assim, essa imagem-objeto torna-se um importante e instigante instrumento de disseminação de conteúdo histórico e cultural, extremamente importantes para a construção e difusão da memória histórica. Dentro deste contexto e em meio ao infinito arcabouço imagético está a caricatura e o seu vasto e diversificado conjunto de imagens em uso na imprensa em toda a parte ao longo dos últimos cinco séculos e que pontuam, não apenas a vida cotidiana, mas também social e cultural das sociedades. É por meio das ilustrações satírico-humorísticas que compõem este multifacetado campo do humor gráfico destacadas nas páginas dos jornais e revistas publicados no transcorrer do tempo que obtemos um importante e valioso compêndio 
memorial do pensamento e práticas sociais e culturais que marcaram os mais diversos e distintos períodos históricos das sociedades. Não obstante, apesar de tais aspectos hoje reconhecidos quase que de forma consensual pelos estudiosos das mais diversas áreas do conhecimento, a caricatura levou um longo tempo para ser legitimada enquanto fonte documental de pesquisa histórica.

É em torno desta problemática que este trabalho se debruça no sentido de trazer à tona, os nuances que caracterizaram a complexa construção historiográfica da iconografia caricatural que permanece até hoje, um campo dos mais desafiantes para os pesquisadores e demais profissionais da história. Contudo, para chegarmos a uma compreensão sobre esse fenômeno específico, faz-se necessário, antes disto, uma abordagem sobre outro do qual este é decorrente e que diz respeito ao modo problemático com que os historiadores se apropriaram, ao longo do tempo, das fontes visuais enquanto documentos de valor histórico. Por esta razão, antes da abordagem sobre a caricatura aqui proposta, o tópico a seguir tentará dar conta, de forma breve, dos nuances principais envolvendo a inserção da imagem iconográfica no campo da história.

\section{A INSERÇÃO DA ICONOGRAFIA NA HISTÓRIA}

Apesar de o interesse da historiografia pela imagem vir ocorrendo desde os primeiros trabalhos da História da Arte, no século XIX, como aponta Meneses (2003), a discussão sobre a apropriação da iconografia no campo de estudos da História, enquanto documento histórico, é uma abordagem relativamente recente e que permanece provocando os historiadores a uma reflexão cada vez mais profunda acerca do potencial cognitivo e testemunhal do documento visual. As contribuições de natureza epistemológicas e metodológicas apresentadas pela Nova História que, conforme esclarece Burke (2004), trata-se de uma expressão que foi popularizada pelo livro La nouvelle histoire (1978), editado por Jacques Le Goff e outros, como se sabe, foram determinantes para o avanço dos estudos historiográficos sobre os mais diversos tipos de suportes imagéticos e sua significação cultural. Foi por meio das novas premissas surgidas a partir da associação da história com outras disciplinas, tais como a antropologia, linguística e a semiótica, alargando desta maneira o seu alcance disciplinar que e se distanciado dos pressupostos da história ortodoxa, que os historiadores puderam investir na formulação de novos problemas, abarcando outros objetos até então não contemplados por 
estes. Sensível às interrogações do presente, a história se aliou à antropologia e se interessou pelos aspectos simbólicos e culturais da sociedade (REIS, 2000, p.113).

Ao analisar o potencial da iconografia para a História, Vovelle (1997) defende que "a partir da iconografia, podemos constituir toda uma série de dossiês pelo ângulo de uma história temática, de uma história-problema, como atualmente se prefere conceituar [...]" (VOVELLE, 1997, p. 178). Ao fazer menção a concepção de amplitude da documentação histórica na linha de pensamento da Nova História, este autor acredita que é possível, portanto, a partir das imagens, se conhecer a história social de um dado tempo, e não apenas dos grupos engajados na política. Ainda de acordo com este autor, as imagens são ao mesmo tempo, testemunhas e 'construtoras' do real, a medida que relata e que contribui, por si só, para construir o acontecimento em toda sua espessura política, social e cultural (VOVELLE, 1997).

Não obstante, conforme relata Meneses (2003) ao fazer uma análise da atenção dos historiadores acerca da problemática envolvendo a inserção dos suportes imagéticos enquanto fonte documental, a contribuição permanece sendo ainda insatisfatória. Diz este autor que:

\begin{abstract}
Mesmo quando há referência, é mínima ou pouco relevante: nos três volumes do que já foi considerado um manifesto da História Nova, capitaneados por Jacques Le Goff e Pierre Nora, não se encontram entre os novos problemas, novos objetos e novas abordagens mais que um capítulo dedicado ao "filme" e outro à "arte". [...] Os capítulos reservados aos "documentos iconográficos" da História Social, ou às "fontes áudio-visuais" na História Cultural, respectivamente em Sources et méthodes en Histoire Sociale e Pour une Histoire Culturelle são de uma superficialidade constrangedora (MENESES, 2003, p. 10).
\end{abstract}

Essa 'invisibilidade visual' dos historiadores, vale salientar, é uma problemática tratada por diversos autores (CHARTIER, 2002; PESAVENTO, 1993; BURKE, 2004; PAIVA, 2002), para ficar apenas nestes. Suas raízes históricas estão em vários fatores, especialmente na supervalorização das fontes escritas em detrimento do vasto e valoroso registro das narrativas imagéticas. Por muito tempo, o interesse dos historiadores se manteve restrito ao campo de estudos da História da Arte que, por sua vez, arraigada aos princípios advindos da história tradicional, privilegiou alguns artefatos imagéticos com valores artísticoculturais (PAIVA, 2006, p. 17).

Desta maneira, a utilização de imagens permaneceu na França por um longo período, como objeto de análise reservado à história da arte. "Por falta de interesse ou de competência, os historiadores das sociedades ou das culturas negligenciaram durante muito tempo as fontes 
iconográficas, deixadas à erudição museográfica ou ao comentário estético" (CHARTIER, 2002, p. 405). Foi o que ocorreu, por exemplo, com as diversas modalidades iconográficas que compõem o universo da caricatura que, apesar de se revelar uma das mais ricas fontes documentais da modernidade, demorou um certo tempo para despertar o interesse dos historiadores, conforme se verá no tópico a seguir.

\section{A CARICATURA NO CAMPO DA HISTÓRIA}

Como defendem alguns autores, dentre eles Fonseca (1999), ninguém pode negar a importância do desenho humorístico na imprensa, seja como documento histórico, como fonte de informação social e política, como termômetro de opinião, fenômeno estético, expressão artística ou como simples forma de diversão e passatempo. Não obstante, esta máxima por muito tempo não foi aplicada à caricatura e suas mais variadas formas de expressão, dentre as quais estão a charge, o cartum, a caricatura pessoal e os quadrinhos, as quais demoraram um certo tempo para serem levadas a sério pelos cientistas sociais, dentre os quais, os historiadores. Em parte, isso se deu devido à própria constituição artística estético-visual e conteúdo ideológico de que essas se fazem portadoras e que requerem uma atenção especial.

Por esta razão, a arte cômica permanece sendo um objeto enigmático, ambíguo, fugidio, e sempre desafiante para o historiador e outros estudiosos, sobretudo, por não permitir assimilação linear. É o caso, por exemplo, das mais variadas formas de ilustrações satírico-humorísticas que compõem o vasto universo da caricatura ${ }^{2}$. Acolhida contemporaneamente pela denominada corrente Historia Cultural, independentemente de não haver alcançado a legitimação plena, a caricatura adquiriu a condição de fonte documental, contudo, sua análise impõem obstáculos metodológicos de vulto (SILVEIRA, 2009, p. 23). A opinião é compartilhada pelo historiador Gawryszewsky (2008), para quem apesar de ter se tornado um termo usual e alvo de estudos de diversos campos do saber, a caricatura em suas diversas modalidades permanece sendo uma valiosa fonte documental a espera de estudos mais profundos. Situada no campo específico do humor gráfico e atrelada à vasta produção

\footnotetext{
${ }^{2}$ A palavra caricatura deriva do verbo italiano carcicare (carregar, sobrecarregar, com exagero) e aparece usada pela primeira vez por A. Mosini quando este se referiu a Diverse Figure, uma coleção lançada em 1646 como uma serie de gravuras chamadas de ritratini carichi (retratos carregados), realizadas a partir de desenhos originais dos irmãos Agostini e Annibale Carracci, satirizando tipos humanos das ruas de Bolonha”. Mosini foi o primeiro a modificar o verbo caricare para o substantivo caricatura, embora Bernini foi quem introduziu o termo na França quando visitou Partis em 1665. Mas foi Thomas Brown quem usou o termo na Inglaterra no sex XVII, para descrever trabalhos de arte italianos. Porém foi somente no sex XVIII que o termo entrou para os dicionários e gradualmente se popularizou (FONSECA, 1999).
} 
dos gêneros satírico-humorísticos em uso na imprensa, a caricatura vem se colocando, ao longo da história, com um dos mais desafiantes objetos de estudo para o campo das ciências humanas e, de modo especial, para a história.

Uma parte dos estudos se volta ao imbróglio envolvendo os vários sentidos em torno do próprio termo caricatura, o qual por não desfrutar de uma definição consensual termina apontando para conceitos diversos e distintos, tanto dentro como fora do mundo acadêmico. Essa variação conceitual está associada aos dois modos com que o termo passou a ser apreendido e disseminado ao longo do tempo. No primeiro deles, o termo caricatura é concebido de maneira estrita, enquanto sinônimo para os desenhos cômicos que em geral, ridicularizam a pessoa humana a partir do exagero dos traços fisionômicos característicos destacados. Neste caso, é comum o emprego da expressão caricatura pessoal. Além deste, a expressão caricatura é concebida de modo mais abrangente e equivale à designação geral atribuída a uma variedade de desenhos satírico-humorísticos em circulação na imprensa, a exemplo da charge e do cartum. É esta, por exemplo, a visão conceitual apresentada por um dos principais estudiosos do assunto, Joaquim da Fonseca para quem, apesar de ser definida de forma restrita como o desenho da pessoa humana, de modo geral, a caricatura abrange formas como "a charge, o cartum, o desenho de humor, a tira cômica, a história em quadrinhos de humor, o desenho animado e a caricatura propriamente dita, isto é, a caricatura pessoal (FONSECA, 1999, p. 17). A visão é compartilhada com outros autores, a exemplo de José Marques de Melo, pioneiro nos estudos dos gêneros jornalísticos no Brasil e que também acrescenta desenhos como a charge, o cartum e as Histórias em Quadrinhos como tipos específicos caricaturais presentes no jornalismo (MELO, 2003).

Além de englobar a concepção de modo estrito do termo, como se vê, esse segundo modo conceitual abarca todas as demais modalidades pertencentes ao campo do humor gráfico, do qual a caricatura passa a ser, portanto, sinônimo, assumindo, dessa maneira, a condição de hiper-gênero. Não obstante, além de imbricar esses dois campos específicos, essa definição generalista do termo caricatura termina por causar um certo imbróglio no processo de distinção entre as diferentes formas de expressão gráficas do humor, cujas distinções conceituais já foram alvos de estudos de vários autores (ver: LAGO, 1999; GAWRYZEWSKY, 2008; RAMOS, 2009). Ao fazer um estudo de revisão bibliográfica a respeito dessa problemática, o historiador Alberto Gawryszewski destacou a diversidade de definições e conceitos em torno do termo caricatura, chamando a atenção para a necessidade de um olhar mais criterioso em torno do assunto. $\mathrm{O}$ autor, do mesmo modo, chama a atenção 
para o fato de que os pesquisadores precisam aprofundar mais o debate teórico em torno desse tipo de fonte abordando, sobretudo, a diferenciação entre as distintas formas do humor gráfico, especialmente, da caricatura (GAWRYZEWSKY, 2008).

Situada num universo da estética artística 'marginalizada', a caricatura foi, por muito tempo, ignorada pelos historiadores que preferiam voltar-se para outros tipos de manifestações iconográficas socialmente mais valorizadas, a exemplo da pintura clássica, dentre outras. No seu texto intitulado: O Arsenal do Cartunista, E. H. Gombrich (1999) destaca que:

\begin{abstract}
Os historiadores costumam achar que tem documentos mais importantes e mais pertinentes a estudar nos papeis e discursos públicos de um período e, geralmente deixam os velhos cartuns para os compiladores de histórias ilustradas populares, onde essas garajutas toscas e muitas vezes enigmáticas aparecem lado a lado, de forma muito incômoda, com retratos, mapas e figuras de cerimonias e assassinatos (GOMBRICH, 1999, p. 127).
\end{abstract}

Segundo este renomado autor e pesquisador das artes visuais, o historiador profissional da arte pouco ocupou-se com o jornalismo gráfico e a sua vasta massa de estampas efêmeras de propagandas, folhetos e cartuns que, do século XVI em diante, foram produzidos em volume crescente. Espaço este preenchido por grandes artistas do desenho e da pintura, a exemplo de Honoré Daumier, pintor, chargista e ilustrador francês conhecido como Michelangelo da caricatura e mestres da litografia, no século XVI. O pouco interesse por parte dos profissionais da história pelo universo do humor gráfico também pode ser constatado através das primeiras grandes obras publicadas acerca do tema, em sua grande maioria de autores de outras áreas, dentre as quais se destacam Histoire de la Caricature Moderne (1885), de autoria do escritor romancista francês Champleury, publicada no final do século XIX; Histoire de la Caructure et du Grotesque dans la Literature ed dans I'Art (1875), do inglês Thomas Wright, ambas ainda não traduzidas para o português; e a obra de Herman Lima, Historia da Caricatura no Brasil, publicada nos anos 1960 e que se tornou um clássico no país, mantendo-se por muito tempo como a grande referência para os estudos sobre o surgimento e desenvolvimento da caricatura nas terras brasileiras.

$\mathrm{O}$ interesse dos historiadores pelas ilustrações satírico-humorísticas que tanto caracterizam o universo da caricatura passou a se desenvolver de maneira mais concreta, ultrapassando as fronteiras da história da arte que, vale dizer, dentre as modalidades estudadas, também contemplava as da arte cômica, a partir do avanço dos estudos em torno do humor e dos aspectos socioculturais do riso, no século XIX. Algo que se tornou uma das 
problemáticas de interesse da corrente da História Cultural, por meio da qual, instigados pelo conceito de representação, os historiadores adeptos da Nova História enriqueceram os debates em torno da produção e consumo de imagens, da criação e da apropriação das mesmas, como objeto e fonte de pesquisa. Com a multiplicação das fontes de pesquisa, a iconografia tornouse cada vez mais utilizada pela História Cultural para o estudo das representações das ações humanas na história. Dentro deste contexto, conceitos como os de 'representação' 'apropriação' passaram a ocupar um lugar de destaque nos estudos culturais em torno das imagens.

Parte destes conceitos, encontra-se filiada às ideias apresentadas por Roger Chartier, historiador vinculado à historiografia francesa e defensor da historia cultural, para quem a representação é um fenômeno associado diretamente às práticas culturais que dão sentido à vida social ${ }^{3}$. Para ele "o objeto da historia cultural é identificar o modo como em diferentes lugares e momentos, uma realidade social é construída, pensada, dada a ler" (CHARTIER, 2002, p.16). E, neste sentido, sem sombra de dúvidas, os diversos tipos de ilustrações caricaturais empregados pelos desenhistas de olhar crítico e sagaz ao longo da história, revelam-se um objeto revelador, fazendo vir à tona, por vezes, realidades sociais nem sempre explícitas nos demais modos de narrativas compartilhadas.

Destarte, embora seu poder de desvelar a verdade, a exemplo de objetos históricos mais respeitados, deva ser relativizado, não há dúvida de que o estudo da arte cômica e, em especial, o da caricatura, oferece um novo e estimulante descortino do tempo vivido (SILVEIRA, 2009, p. 23). Nesse sentido, na condição de fonte documental que remete inevitavelmente ao encontro de um conjunto de elementos e práticas socioculturais e políticas extremamente expressivo e representativo, tendo no riso satírico o seu fio condutor, a caricatura passou a destacar-se como um importante objeto catalisador, não apenas de registros temporais históricos, mas também dos padrões de mentalidade individual e coletiva cultivados pelos sujeitos na linha do tempo, como defendem vários autores.

Desta maneira, os cartuns e, portanto, a caricatura, devem ser estudados com curiosidade perplexa, não tanto pelo que podem dizer sobre acontecimentos históricos quanto pelo que revelam acerca de nossas próprias mentes (GOMBRICH, 1999, p. 127). Dentro deste prisma, para além de se desvendar enigmas ilustrados, ao se observar esses tipos de desenhos

\footnotetext{
${ }^{3}$ Ao discutir os pressupostos de sua história cultural na introdução de sua obra A História Cultural: entre prática e representações, Roger Chartier procuraria se colocar nos anos de 1980, em uma terceira frente de batalha para superação das lutas intelectuais que se travavam desde os anos de 1960 e 1970, entre as teorias e métodos estruturalistas e subjetivistas dentro da história cultural francesa.
} 
busca-se descobrir que papel a imagem pode representar nos escaninhos de nossa mente. Por isso, quando estudamos os cartuns, estudamos o uso de símbolos num contexto circunscrito (GOMBRICH, 1999, p. 128). Por essa razão, os estudos em torno do humor e suas diversas formas de manifestações, dentre os quais, se insere a caricatura, são reservados ao campo da História Cultural que vem oferecendo uma importante contribuição nos estudos contemporâneos.

\section{OS HISTORIADORES E O INTERESSE PELO RISO}

Como se pode perceber até aqui, o desenvolvimento dos estudos em torno da caricatura no campo da história está associado em grande parte, ao avanço do interesse da academia pelo fenômeno do humor e, de modo especial, do riso satírico que, por sua vez, tem no universo das práticas sociais e políticas, o seu grande arsenal inspirador. É em torno das múltiplas dimensões que revestem o humor enquanto fenômeno eminentemente humano e de caráter sociocultural que o olhar dos historiadores se volta, no intuito de dar conta dos aspectos social, político e cultural que estão por trás de tudo daquilo que se faz risível ${ }^{4}$. Nesse contexto, ganha destaque a contribuição do historiador George Minois que, especialmente através de sua obra Historia do Riso e do Escárnio, apresenta uma abordagem em torno da prática e da teoria do riso, destacando a força social, política e cultural que este revela ao longo da história da humanidade. Isto sem falar na contribuição advinda de estudiosos de outras áreas, dentre os quais se destacam o filósofo Henri Bérgson (2004) e o filólogo Vladmir Prop (1992), os quais ampliaram a discussão em torno da função política e social do riso, destacando estas enquanto elementos idiossincráticos da sátira e da caricatura.

Alguns dos autores, a exemplo de Minois (2003), chamam a atenção para o fato de que é na sátira política que o riso encontra, especialmente a partir do século XIX, seu terreno predileto. Segundo Minois (2003) a caricatura desabrochou no século XVII, denominado de o 'século de zombaria', contudo, foi só a partir do século seguinte que esta adquiriu uma dimensão social, tornando-se uma arte autônoma. Os debates parlamentares, o início da democracia, a liberdade de imprensa, criam as condições ideais para um grande debate de ideias em que a ironia é chamada a desempenhar um papel essencial (MINOIS, 2003, p.482). Foi em meio a esse cenário e combinação de elementos socioculturais e políticos que a

\footnotetext{
${ }^{4}$ Dentre os estudos que dão desdobramento a essa temática, discutindo as diversas categorias ligadas ao riso, dentre elas, a sátira, está o trabalho da pesquisadora Verena Alberti (2002).
} 
caricatura avançou legitimando-se, ao longo do tempo, como uma das mais legítimas manifestações artístico-culturais em uso na sociedade moderna. Não obstante, é importante salientar que trata-se de uma das mais antigas expressões do humor visual e que tem, conforme ressalta Fleiuss (Apud SILVA, 1990), nas tradições visuais europeia e asiática, desde a antiguidade, um de seus marcos históricos.

Ao traçar o itinerário histórico da caricatura, relacionando-a com o período da Revolução Francesa, Michel Vovelle faz um importante registro ao afirmar que:

Ela existia dentro dos espaços de tolerância das próprias condições de censura do Antigo Regime. Todos conheciam pelo menos aquela imagem inspirada pela Assembleia dos Notáveis em 1787, em que aparece o ministro Calonne, vestido de macaco cozinheiro, perguntando a um bando de aves em que molho preferiam ser devoradas (VOVELLE, 1997, p. 165).

Numa breve abordagem sobre o tema, num dos capítulos do seu livro Imagens $e$ Imaginário na História - fantasmas e certezas nas mentalidades desde a Idade Média até o século $X X$, Michel Vovelle destaca o uso da caricatura como arma de combate dentro do jogo político, associando-a à imprensa revolucionária francesa daquela época. A caricatura foi muito vivaz a partir de 1798, culminando sem dúvida entre 1790 e 1792, quando se desencadearam os confrontos entre os partidos, não poupando a pessoa do rei, cristalizando-se em torno de certos temas (VOVELLE, 1997, p. 165). Voltando à Minois (2003), este autor destaca, entretanto, que desde o início do século XVIII a caricatura passara a atacar a esfera política em parceria com os panfletos. E em março de 1737, aparece uma estampa satírica que faz rir Londres inteira: a festa da bunda de ouro. Trata-se de uma gravura com a imagem do rei George II, postado sobre um pedestal, nu, visto de costas, soltando um enorme peido: "Os ventos do leste, do sul e do sudoeste levantam-se em tempestade", diz a inscrição - citação da Eneida - sobre o pedestal (MINOIS, 2003, p. 305). Trata-se aqui, do início de uma série interminável da produção de ilustrações satíricas grotescas que tinha como principal função, levar os monarcas, aristocratas e outras figuras da esfera pública para o universo da ridicularização, instigando o efeito derrisório que tanto caracteriza o riso satírico.

Numa das obras que se tornou referência na pesquisa sobre a caricatura, no Brasil, Joaquim Fonseca (1999) detalha que enquanto manifestação satírico-humorística associada aos fatos e personagens do mundo da política, a caricatura teve o seu berço no século XVII, na Holanda, que tornou-se o centro de lançamento de uma quantidade de enorme de estampas satíricas contra a política do 'grande monarca'. O país possuía artistas dos mais hábeis e os 
melhores gravadores da Europa - dentre eles, Jacques Callot e Romain De Hooghe-, e desenvolvia uma campanha contra o absolutismo do rei francês, Louis XIV (FONSECA, 1999, p. 27). Mas, conforme aponta este mesmo autor, o salto para o outro lado do mundo se deu na Inglaterra, no início do século XVIII. Por volta de 1740, o impresso de estampas Arthur Pond publicou um conjunto de gravuras com 25 caricaturas feitas de desenhos originais dos italianos Annibale Carraci; G. F. Barbier; Piefrancesco Mola; Pier Leone Ghezi e do francês Jean Antoine Watteau, sem falar na coleção de Pond que causou um grande sucesso (FONSECA, 1999, p.28)

Embasada no caráter eminentemente sociocultural que acompanha o riso, e mais ainda, no aspecto político que, de modo geral, fundamenta o riso satírico, não demorou muito para que as manifestações caricaturais se expandissem para todos os continentes do mundo, tornando-se uma das formas de narrativa visual mais populares em uso. Não obstante, a penetração desta modalidade artístico-cultural nas sociedades não ocorreu de maneira uniforme ou sempre tranquila, conforme demonstram alguns dos estudos historiográficos sobre a caricatura. No Brasil, por exemplo, a legitimação da arte caricatural enfrentou uma certa resistência, conforme se verá a seguir.

\section{A LEGITIMAÇÃO HISTÓRICA DA CARICATURA NO BRASIL}

Em se tratando do Brasil, os registros historiográficos da caricatura se voltam, em sua maioria, para os dados referentes à instauração da imprensa satírica no período imperial e da ampla propagação desta na virada do século XVIII para o século XIX ${ }^{5}$. Para além deste panorama que, vale salientar, não faz parte do interesse deste trabalho descrevê-lo, tendo em vista os diversos estudos já publicados a respeito, poucos são os registros que dão conta dos impasses socioculturais que os desenhos artísticos de cunho satírico-humorísticos enfrentaram até se tornarem bem aceitos na sociedade. Um dos pesquisadores a se atentar para essa realidade foi o historiador Marcos Antonio da Silva, autor de alguns dos primeiros e mais marcantes trabalhos sobre o humor gráfico no país, publicados nas últimas décadas ${ }^{6}$. Ao

\footnotetext{
5 Como apregoam diversos autores (LIMA, 1963; FONSECA, 1999; SALIBA, 2002), as condições para o desenvolvimento da caricatura no país começaram a ser criadas a partir do primeiro estabelecimento litográfico no Rio de Janeiro, no final do século XIX e acaba se espalhando pela corte durante os anos 1930, época em que surgem diversas oficinas, dentre elas, as de Larré, Resnburg, Briggs, Simon e a de Fleuiss, apontado como por alguns autores com o fundador do primeiro jornal ilustrado, o Corcundão, no Recife, em 1831.

${ }^{6}$ Além de dissertação de mestrado e tese de doutorado, o historiador é autor de vários artigos científicos e obras voltadas ao estudo do humor visual brasileiro, dentre as quais se destacam: Prazer e poder do Amigo da Onça
} 
discutir a historicidade do humor visual nas terras brasileiras, Silva (1990) chama a atenção o imbróglio envolvendo o processo de legitimação da caricatura no campo erudito. Em sua obra Caricata República - Zé Povo e o Brasil, este mesmo autor faz um registro importante ao destacar que a consolidação do caricatural se deu em meio à diferenciação dessa plástica em relação à visualidade erudita, numa discussão acirrada envolvendo intelectuais e artistas.

Silva (1990) destaca a luta traçada no início do século XX pelo historiador e especialista em humor visual Max Fleiuss em inserir a caricatura no universo da produção cultural e artística do país, bem como em eventos destes campos, usando como um de seus argumentos o fato de, já naquela época, tratar-se de uma modalidade expressiva de grande cunho popular. Tal discussão, conforme relata o pesquisador, perpassava os campos interpretativos em torno da concepção da cultura brasileira, produção intelectual e artística, de tal modo que:

A separação entre caricatural (ou popular) e erudito foi assim transformada em relação entre alma (ou espontaneidade) e cultura, retirando parcialmente o gênero caricatural desse último e prestigioso espaço. Permaneceu, entretanto, a visão da caricatura como parte da historicidade da plástica brasileira (SILVA, 1990, p. 77).

Por trás dessa polêmica em torno da legitimação da caricatura, é importante frisar, estava a concorrência entre desenhistas e os diversos intelectuais que passaram a disputar lado a lado, seus espaços de atuação profissional dentro do cenário de produção cultural em que as revistas ilustradas ${ }^{7}$ se destacavam como depositários ilustrados da vida social brasileira, elevando consigo o desenho humorístico a um patamar privilegiado. Nesse contexto, os caricaturistas passaram a ter o reconhecimento de sua produção como digna de menção e vigência próximo ao de outros artistas e intelectuais, conforme descreve Silva (1990).

Assim, a valorização profissional dos desenhistas de humor se deu paralelamente à elaboração de uma hierarquia entre campos artísticos "sério" e "humorístico" ao mesmo tempo em que também se superava a questão da desqualificação da narrativa visual frente às demais modalidades textuais que compunham os periódicos em circulação na sociedade

1943 - 1962 (1989); A caricata República: Zé povo e o Brasil (1990); e, por último Rir das Ditaduras: os dentes de Henfil - Fradim - 1971/1980 (2018).

${ }^{7}$ De acordo com Teixeira (2001), o Brasil mantém uma posição de destaque no tocante à tradição de produção do humor gráfico, havendo se consolidado, na metade do século XIX, como um dos maiores produtores do gênero no mundo, superando França e Inglaterra, pioneiras na impressão de revistas de humor gráfico. Dentre os periódicos de grande repercussão na época, destacaram-se: A Marmota Fluminense (1849), Semana Ilustrada (1860), Vida Fluminense (1868), Revista Ilustrada (1876), Psif! (1877), O Besouro (1878), A Brucha (1896) e Don Quixote (1898). 
naquela época, incluindo a fotografia que mantinha uma certa áurea de prestígio. Não obstante, a despeito de se tratar de uma arte manual, a caricatura apresentava uma vantagem diante da fotografia que era a de, manifestar de forma breve, através de imagem, uma narrativa de teor crítico indo muito além da função ilustrativa. E, desta maneira, o humor visual brasileiro foi legitimado a partir de seu poder de castigar costumes e sua capacidade de síntese (SILVA, 1990, p. 78).

Tais características da narrativa visual humorística brasileira, por sua vez, foram registradas com riqueza de detalhes no livro História da caricatura no Brasil $^{8}$, de autoria do jornalista, crítico literário e escritor Herman Lima. Em sua obra, que divide-se em quatro volumes e se tornou uma enciclopédia sobre a historiografia da caricatura no país, lançada em 1963, depois de 20 exaustivos anos de pesquisa, o autor faz um apanhado sobre a origem e o desenvolvimento da arte caricatural no Brasil durante a primeira metade do século $\mathrm{XX}$, preenchendo, assim, uma lacuna deixada pelos historiadores brasileiros até então pouco voltados para este objeto de estudo. Nela, para além do registro histórico dos principais nomes que se destacaram como os primeiros e principais caricaturistas no país, é possível conferir a evolução do traço na evolução do gênero em que o Brasil se tornou referência em todo o mundo, e a variação temática presente na narrativa caricatural que, conforme já foi aqui destacado, fazem desta modalidade visual, uma fonte significativa para a construção de narrativas históricas.

A obra de Lima (1963) apresenta, através dos desenhos caricaturais, uma síntese satírico-humorística dos principais acontecimentos políticos e socioculturais que marcaram a vida do país na virada do século XIX para o século XX. Assim, foram explorados temas como as eleições, a escravidão, a monarquia, questões de cunho religioso envolvendo a Igreja Católica, a Maçonaria e a Monarquia, a Revolução de 30 e a política internacional. O trabalho de Herman Lima foi revisitado e ampliado recentemente pela obra História da Caricatura Brasileira- volume I (2012), de autoria do historiador e caricaturista Luciano Magno que trouxe para o âmbito da historiografia da caricatura recente, uma contribuição advinda de um profissional da história, reduzindo, desta maneira, a lacuna ainda existente de trabalhos deste porte sobre a produção satírico-humorística ilustrada brasileira? ${ }^{9}$

\footnotetext{
${ }^{8}$ LIMA, Herman. Historia da Caricatura no Brasil. Rio de Janeiro:José Olympio, 1963.

${ }^{9}$ Afora os nomes dos pesquisadores das mais diversas áreas do conhecimento humano e dos historiadores que se voltaram com maior atenção para os estudos das idiossincrasias da produção da caricatura no Brasil, é importante ressaltar que há no mercado editorial, uma infinidade de trabalhos advindos do punho de muito dos
} 
Diante das considerações aqui expostas, fica evidente a importância da publicação dessas obras acerca do humor gráfico que compreende a caricatura enquanto lugar privilegiado da sátira política. Além de destacar o grande arsenal histórico desta consagrada vertente do humor gráfico, os trabalhos despertam a atenção para o potencial cognitivo e memorial das imagens de que os traços caricaturais se fazem representantes. Algo que, ao que parece, permanece na condição de um desafio para os mais diversos estudiosos voltados ao trabalho de desvendar o poder enigmático e catalisador de que a imagem em si se faz portadora e que, como defendem vários dos pesquisadores, a exemplo de Paiva (2002) e Silva (1989), revela-se um dos mais instigantes e valiosos fenômenos para o campo das ciências sociais e humanas, do qual a História se inclui como uma das mais significativas disciplinas.

\section{CONSIDERAÇÕES FINAIS}

Conforme se pôde constatar neste artigo, a trajetória da iconografia no campo da história enquanto fonte documental de grande significação social, política e cultural, é permeada de embates de natureza epistemológica e permanece se configurando um desafio para a historiografia. Os nuances em torno do lento e complexo trajeto de legitimação da caricatura e suas várias formas de expressão satírico-humorísticas, desde sua origem e desenvolvimento no século XVI aqui analisados, servem de parâmetro para uma visão mais clara desta problemática que, embora mais tranquila nos dias de hoje, ainda persiste a espera de uma atenção mais aprofundada por parte dos historiadores, bem como de outros profissionais, a exemplo dos estudiosos do campo da cultura visual. Por esta razão, pode-se afirmar tratar-se de uma relevante proposta de trabalho historiográfico ainda em construção. Como ressalta Meneses (2003), é inegável que houve um avanço e que a História, a despeito do que era feito antes da contribuição da Escola dos Annales, privilegia a função da imagem para além de seu caráter eminentemente ilustrativo. Nesse sentido, não se pode deixar de evidenciar que "antes de tudo, a imagem se impõe como testemunho" (VOVELLE, 1997, p. 170).

Esse caráter testemunhal desempenhado pelos mais diversos tipos de narrativas imagéticas, dentre as quais estão as lustrações satírico-humorísticas, tem, aos poucos, ampliado o olhar dos historiadores para as múltiplas possibilidade de se trabalhar com os

próprios caricaturistas muitos dos quais são citados por Magno (2012) em sua enciclopédia recente sobre a história da caricatura brasileira. 
suportes visuais enquanto objetos e fontes de pesquisa e de trabalho variado, pautados no infinito potencial de vestígios do passado que esses se fazem portadores. Nesse sentido, as atenções tem se voltado em grande parte para as ilustrações iconográficas de maior destaque no amplo e diversificado universo da caricatura, a exemplo da charge, do cartum e da caricatura pessoal que permanecem tendo uma boa circulação na imprensa até os dias de hoje. Não obstante, conforme foi ressaltado por meio deste trabalho e de alguns outros que o antecederam, é necessário um olhar mais criterioso sobre tais objetos, levando em consideração, de modo especial, o aspecto plural e multifacetado que envolve a caricatura enquanto uma modalidade de expressão gráfica do humor ainda distante de conclusões consensuais, sobretudo, do ponto de vista conceitual. Afora isso, não se pode negar o fato de se tratar aqui de um objeto que aponta para o plural e complexo fenômeno carregado de sentido social, político e cultural de que as ilustrações satírico-humorísticas se tornam fieis representantes que é o riso.

Por fim, as considerações aqui apresentadas, parecem ir ao encontro do que afirma o estudioso do humor sob a ótica da história cultural, Elias Thomé Saliba. Ao apresentar um balanço provisório acerca da contribuição da História Cultural do humor até aqui, ele destaca que foi só nas últimas décadas, no ambiente intelectual difuso, mas de largo predomínio, das chamadas "viradas linguísticas" e "viradas subjetivas" que o humor vem encontrando guarida tanto nos vastos castelos quanto nas choupanas mais escusas da historiografia (SALIBA, 2017, p. 18). Algo totalmente compreensível se considerado o fato de que, trata-se aqui de uma frente de estudos que tem como objeto central o humor, esta experiência humana tão amplamente variada e diversificada como disseminada pelos mais variados campos do conhecimento e das práticas socioculturais.

\section{REFERÊNCIAS}

BERGSON, Henri. O riso: ensaio sobre a significação do cômico. São Paulo: Martins Fontes, 2004.

BURKE, Peter. Testemunha ocular: história e imagem. Bauru: Edusc, 2004. . O que é História Cultural. Rio de Janeiro: Jorge Zahar Editor, 2005.

CHARTIER, Roger. A História Cultural: entre práticas e representações. Rio de Janeiro: Bertrand Brasil, 2002. 
FERRO, Marc. O filme: uma contra-análise da sociedade? In: LE GOFF, Jacques; NORA, Pierre (Orgs.). História: novos objetos. Rio de Janeiro: Paz e Terra, 1992.

FONSECA, Joaquim da. Caricatura: a imagem gráfica do humor. Porto Alegre: Artes e Ofícios, 1999.

GAWRYSZEWSKY, Alberto. Conceito de caricatura: não tem graça nenhuma. Domínios da Imagem. Londrina. V. I, P. 7-26. Maio 2008. Disponível em $<$ http://www.uel.br/revistas/uel/index.php/dominiosdaimagem/article/view/19302>. Acesso em: 12. Nov. 2017.

GOMBRICH, E. H. O Arsenal do Cartunista. In: Meditações sobre um cavalinho de pau outros ensaios sobre a teoria da arte. São Paulo: Edusp, 2001.

LIMA, Herman. A história da caricatura no Brasil. Rio de Janeiro: José Olympio, 1963.

MAGNO, Luciano. História da caricatura brasileira. Gala Edições de Arte, Rio de Janeiro, 2012.

MELO, José Marques. Jornalismo Opinativo: gêneros opinativos no jornalismo brasileiro. Campos do Jordão: Mantiqueira, 2003.

MENESES, Ulpiano Toledo Bezerra de. Fontes Visuais, Cultura Visual, História Visual: balanço provisório, propostas cautelares. In: Revista Brasileira de História. Volume 23, número 45. São Paulo: ANPUH, 2003. Pp. 11-36. Disponível em: <www.scielo.br.> Acesso em 12 jan 2017.

MINOIS, Georges. História do riso e do escárnio. São Paulo: Editora UNESP, 2003.

PAIVA, Eduardo França. História \& Imagens. Belo Horizonte: Autêntica, 2002.

PESAVENTO, Sandra Jatahy (org). Porto Alegre Caricata: a imagem conta a história. Porto Alegre: EU/Secretaria Municipal da Cultura, 1993.

PROP, Vladimir. Comicidade e riso. São Paulo: Ática, 1992.

REIS, José Carlos. A História, entre a Filosofia e a Ciência. Belo Horizonte: Autêntica, 2011.

SALIBA, Elias Thomé. Raízes do riso: a representação humorística na história brasileira: da Belle Époque aos primeiros tempos do rádio. São Paulo: Companhia das Letras, 2002.

. História Cultural do Humor: balanço provisório e perspectivas de pesquisas. Revista de História, São Paulo, n. 176, p. 01-39, nov. 2017. Disponível em: <https://www.revistas.usp.br/revhistoria/article/view/127332>. Acesso em: 08 mai. 2018.

SILVA, Marcos. Rir das ditaduras: os dentes de Henfil (Fradim - 1971/1980). São Paulo: Intermeios; USP - Programa de Pós-graduação em História Social, 2018.

1989. . Prazer e poder do Amigo da Onça (1943 - 1962). Rio de Janeiro: Paz e Terra, 
SILVEIRA, Mauro César. A batalha de papel: a charge como arma na guerra contra o Paraguai. Florianópolis: Editora da UFSC, 2009.

VERENA, Alberti. O riso e o risível na história do pensamento. Rio de Janeiro: Fundação Getúlio Vargas, 2002.

VOVELLE, Michel. Imagens e imaginário na História. São Paulo: Ática, 1997. 